\title{
Isolation of Good-Quality RNA from Rosa Chinensis, Rich in Secondary Metabolites
}

\author{
Yong Zhang a , Yunting Zhang ${ }^{\mathrm{b}}$, Haoru Tang c, * \\ College of Horticulture, Sichuan Agricultural University, 611130 Chengdu, China. \\ a zhyong@sicau.edu.cn, ${ }^{b}$ asyunting@gmail.com, *, chtang@sicau.edu.cn
}

Keywords: Rosa chinensis, RNA Isolation, CHS gene, CTAB.

\begin{abstract}
Rosa chinensis is being widely investigated because of its extremely high ornamental value and commercial value. Scientists have entered the molecules for its researching level. Extraction of high quality RNA is a primary and key step towards undertaking molecular biology experiments, which is often affected by contaminants, such as pigments, polyphenols, proteins, plant secondary metabolites, and genomic DNA from plant tissues. Here the authors build a new protocol suitable for isolating high-quality RNA from the petals of Rosa chinensis. Based on a CTAB method, the quality of RNA is very pure with little contaminants and makes a figure in gel electrophoresis. After RT-PCR, the $860 \mathrm{bp}$ sequence of chalcone synthase (CHS) gene was obtained to identify the quality of total RNA from Rosa chinensis. In these experiments, The RNA isolated by the improved CTAB method is quite excellent.
\end{abstract}

\section{Introduction}

Rosa chinensis is a traditional famous flower and is one of land- -scape and flower market very important material. The plant tissues are rich in pigments, polyphenols, proteins, plant secondary metabolites and so on, which limits the Isolation of Good-Quality RNA [1,2], especially the ornamental plant petals. Petals RNA extraction is the necessary basis about studying the Chinese rose flower development related gene, color gene and flower gene expression. At present, there are many isolation of Good-Quality RNA method based on CTAB [3-5]. Each plant and its different parts of all have their own characteristics. These characteristics reflect in their structure and composition, so it is difficult to use a kind of method to adapt to all the plant tissue [6]. To Rosa chinensis, petals are rich in various pigment, polysaccharide and other secondary metabolites, having greatly affected extraction of the petals RNA [7]. Authors Adopted the improved CTAB method and changed the RNA extraction protocol, the high-quality RNA successfully isolated. it can be applied directly to RT - PCR, difference display, northern hybridization and test.

\section{Materials and Methods}

\subsection{Materials}

'Fairyland' rose flowers were collected from the College of Horticulture, Sichuan Agricultural University, Sichuan province of China, taking good petals immediately frozen in liquid nitrogen for transportation to the laboratory and stored at $-80^{\circ} \mathrm{C}$ until used.

\subsection{RNA Extraction}

The total RNA was extracted from the petals of rose by modified CTAB method [8].

\subsection{Analysis of RNA Purity and Yield}

Added 5ul RNA to 45ul DEPC-treated water and then measured in a spectrophotometer (Bio photometer, Ep-pendorf, Hamburg, Germany). RNA purity was assessed by the ratios of A260/A280 and A260/A230. RNA yield was calculated based on the Beer-Lambert Law.

\subsection{Assessment of RNA Integrity}

The integrity of RNA was assessed by the brightness and sharpness of 28SrRNA, 18SrRNA and 5SrRNA bands on denaturing 1\% agarose gel. total RNA of gel electrophoresis was stained with 
ethidium bro-mide and visualized using a UV transilluminator and a gel doc system (Syngene, Cambridge, UK).

\subsection{Reverse Transcription and RT-PCR}

The first-strand cDNA was synthesized by using 2ul total RNA with the Revert Aid TM First-Strand cDNA Synthesis Kit (Fermentas, USA) according to the manufacturer instructions. A gene fragment of chalcone synthase gene was amplified using the following primers: forward, 5'-CCKTCHYTGGAYGCNMGRCARGAC-3'; reverse, 5'-GGBCCRAANCCRAANARMACAC C -3'. Polymerase chain reaction (PCR) was performed in a Bio-Rad thermal cycle system with a 25ul reaction mixture containing $2 \mu 1$ of first-strand cDNA, $12.5 \mu 12 \times$ Taq PCR Master Mix (SANGON, Shanghai), $1 \mu 1$ primer RcCHSF and $1 \mu 1$ primer RcCHSR, and $8.5 \mu 1 \mathrm{ddH} 2 \mathrm{O}$. PCR amplification conditions were $94^{\circ} \mathrm{C}$ for $3 \mathrm{~min}$, then 34 cycles of $94^{\circ} \mathrm{C}$ for $1 \mathrm{~min}, 58^{\circ} \mathrm{C}$ for $1 \mathrm{~min}$, and $72^{\circ} \mathrm{C}$ for $1 \mathrm{~min}$, followed by a final incubation at $72^{\circ} \mathrm{C}$ for $10 \mathrm{~min}$, stored at $12^{\circ} \mathrm{C}$.

\section{Result and Analysis}

\subsection{Assessment of the Total RNA}

The obtained RNA was quantified and examined for the possible contamination. The mean yield of RNA extracted by the method was close to $58 \pm 8.25 \mathrm{ng} / \mathrm{g}$ of petals, with the A260/A280 ratio being 1.91 and A260/A230 ratio being 1.79. Total RNA isolated by the improved CTAB, three bands visualized on denaturing $1 \%$ agarose gel, and the brightness of the $28 \mathrm{~S}$ band was approximately twice than that of the 18S RNA band (28SRNA, 18S RNA and 5SRNA). Besides, there is no shining phenomenon near the bands and sample holes, indicating that samples did not contain polyphenols, protein and other contaminations basically (Fig.1). In general, the quantity, purity, and integrity of RNA was well, according to the requirement of experiment.

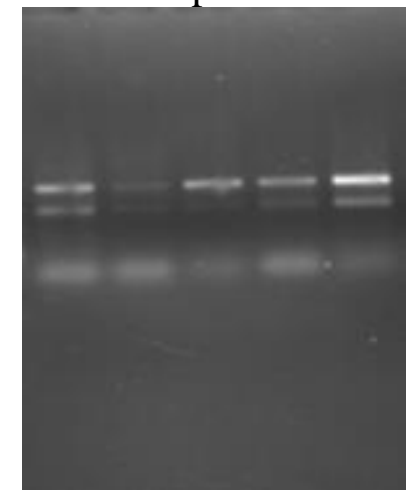

Fig. 1. Total RNA from Rosa chinensis petals using our modified CTAB method

\subsection{RT-PCR Analysis}

The total RNA was isolated from the flower petal of Rosa chinensis 'Fairyland' by improved CTAB, then reverse transcription. Using PCR degenerate primers designed based on GenBank published the conserved sequences of chalcone synthase genes from other plants to amplify cDNA fragments, a new chalcone synthase gene named RcCHS was cloned. The expression patterns of RcCHS in different developmental stages were analyzed by semi-quantitative RT-PCR. The length of RcCHS was 860 bp which encoded 287 amino acids. Homology analysis showed that the RcCHS of Rosa chinensis 'Fairyland' had high homologies with other plants and indicated that CHS in evolution process kept the high conservatism (Table 1).

Table 1. Results of sequence similarity analysis

\begin{tabular}{cccc}
\hline Accession number & Pant & Sore & Identities \\
\hline AB038246.1 & Rosa hybrid & 818 & $98 \%$ \\
HQ423171.1 & Rosa chinensis & 803 & $98 \%$ \\
AB201758.1 & Fragaria x ananassa & 647 & $92 \%$ \\
AF400567.1 & Rubus idaeus & 644 & $92 \%$ \\
JN602374.1 & Rubus hybrid & 518 & $87 \%$ \\
JN391444.1 & Prunus persica & 509 & $87 \%$ \\
\hline
\end{tabular}




\section{Discussion}

CTAB-based methods have recently been used for RNA isolation. In the research, using the CTAB-based buffer containing Naci, PVP, EDTA, Tris-Hcl. because PVP can allow the polyphenols to be separated from nucleic acids by forming complexes with polyphenols through hydrogen bonds [9], added one scoop of PVP when grinding. In the process, the authors used Isopropyl alcohol as precipitation reagent instead of $\mathrm{LiCl}$, it only needs $20 \mathrm{~min}$ to precipitate RNA which greatly shorten the precipitation time comparing with $\mathrm{Yu}$ et al. Through the examination quality of RNA obtained, the improved CTAB is efficient method, which succeed in isolating high-quality RNA from Rosa chinensis in petals with a lot of proteins, polysaccharides, polyphenols, and other impurities.

\section{References}

[1]. Gasic, K., Hernandez, A., Korban, S. S. RNA extraction from different apple tissues rich in polyphenols and polysaccharides for cDNA library construction. Plant Molecular Biology Reporter, Vol. 22 (2004) No. 4, p.437-438.

[2]. Djami-Tchatchoua, A. T., Straker, C. J. The isolation of high quality RNA from the fruit of avocado (Persea Americana Mill.). South African Journal of Botany, Vol. 78 (2012) No. 1, p. $44-46$.

[3]. Macrae E. Extraction of plant RNA. Methods in Molecular Biology, Vol. 362 (2007) No. 353, p. 309.

[4]. Wang, X. H., Xiao, H. L., Chen, G. X., et al. Isolation of High-Quality RNA from Reaumuria soongorica, a Desert Plant Rich in Secondary Metabolites. Molecular Biotechnology, Vol. 48 (2011) No. 2, p. 165-172.

[5]. Wang, L. M., Stegmann, J. P. Extraction of High Quality RNA from Polysaccharide Matrices using Cetyltrimethylammonium Bromide. Biomaterials, Vol. 31 (2010) No. 7, p. 1612.

[6]. Gao, S. C., Shi, J., Wang, S, H., et al. An efficient method for preparation total RNA of peony petals. Journal of He'nan Agricultural Sciences, Vol. 10 (2007) No. 2, p. 93-94.

[7]. Xie, J. R., Cheng, Z. Q., Huang, X. Q., et al. The extraction method of total RNA from Chinese rose petals. Journal of Yunnan Agricultural University, Vol. 22 (2007) No. 4, p. 480-484.

[8]. Yu, D. Q., Tang, H. R., Zhang, Y., et al. Comparison and Improvement of Different Methods of RNA Isolation from Strawberry (Fragria $\times$ ananassa). Journal of Agricultural Science, Vol. 4 (2012) No. 7, p. 51-56.

[9]. Maliyakal, E. J. An efficient method for isolation of RNA and DNA from plants containing polyphenolics. Nucleic Acids Research, Vol. 20 (1992) p. 2381. 